\title{
Kinetics and Mechanism of Hydroxyapatite Crystal Dissolution in Weak Acid Buffers Using the Rotating Disk Method
}

\author{
MAW-SHENG WU, WILLIAM I. HIGUCHI, JEFFREY L. FOX, and \\ MICHAEL FRIEDMAN \\ College of Pharmacy, The University of Michigan, \\ Ann Arbor, Michigan 48109, USA
}

The dissolution rates of synthetic hydroxy. apatite pellets under sink conditions were measured using the rotating disk method. The experimental data were analyzed by means of a physical model that yielded an ionic activity product of $\mathrm{K}_{\mathrm{HAP}}=\mathrm{a}^{10}{ }_{\mathrm{Ca}^{2+}} \mathrm{a}^{6}$ $\mathrm{PO}_{4}^{3-} \mathrm{a}^{2} \mathrm{OH}-=1 \times 10^{-124.5 \pm 1.0}$ that was found to govern the dissolution reaction. Also, a surface resistance factor of $\mathrm{k}^{\prime}$ equal to about $174 \mathrm{sec} / \mathrm{cm}$ was deduced from the data.

A physical model for describing the dissolution rate behavior of human dental enamel and of hydroxyapatite in weak acid buffers under sink conditions was introduced by Higuchi and his collaborators. ${ }^{1-3}$ The model assumed that a hydroxyapatite phase governs the driving force of the dissolution and that the dissolution was essentially diffusion controlled in a diffusion layer adjacent to the enamel surface. The mathematical development also included the consideration of simultaneous diffusion and equilibriums of all species in the system.

This early model enjoyed notable success. ${ }^{1-3}$ It was able to generally account for the effects of buffer types $\left(\mathrm{pK}_{\mathrm{a}}\right)$, buffer concentration, $\mathrm{pH}$, and common ions (calcium and phosphate). Furthermore, an extension of this model showed that the influence of solution fluoride on the dissolution rate may be explained by assuming that a surface exchange of $\mathrm{OH}^{-}$by $\mathrm{F}^{-}$occurs rapidly during dissolution.4

For several reasons, it has been apparent that a more critical study of this model would be necessary. First, the value of $K_{H A P}$

This investigation was supported by USPHS Service Grant DE-1830 from the National Institutes of Health, Bethesda, Md.

Received for publication June 14, 1974.

Accepted for publication November 6, 1975. (defined as $\mathrm{a}^{10} \mathrm{Ca}^{2+} \mathrm{a}^{6} \mathrm{PO}_{4}{ }^{3-} a^{2} \mathrm{OH}_{-}=1 \times 10$ $-124.5 \pm 1.0$ ), the driving force for the dental enamel dissolution reaction, appears to be somewhat low in view of the recent thermodynamic studies, ${ }^{5,6}$ that support a $K_{s p}$ of about $10^{-116}$. Also, our preliminary studies with both human dental enamel and with compressed pellets of hydroxyapatite have indicated that although indeed at low agitation intensities the reaction rates are essentially diffusion controlled, at the high agitation conditions there appears to be a significant contribution to the overall $\mathrm{ki}$ netics from a surface reaction step. In addition, many of the previous studies were conducted with powdered enamel and powdered synthetic hydroxyapatite samples for which the surface areas were only approximately known.

The purpose of the present report is to describe the results of baseline studies with the model, using the rotating disk method for which both the geometry of the dissolution surface and the hydrodynamics in the solution phase near the disk surface are relatively well defined. The physical model and the basic equations have also been modified to take into account crystal-solution surface kinetics and solution penetration of the hydroxyapatite disk as well as diffusion and convection in solution phase. It is noteworthy that Nancollas ${ }^{7}$ has recently seconded the need for studies such as those reported here for the same reasons just presented.

\section{Materials and Methods}

DESCRIPTION OF THE MODEL.-Simultaneous surface reaction and bulk diffusion.-The general model is schematically shown in Fig. ure 1 . When a surface of a compressed pellet of hydroxyapatite crystals is exposed to a well-stirred aqueous buffer solution, there 


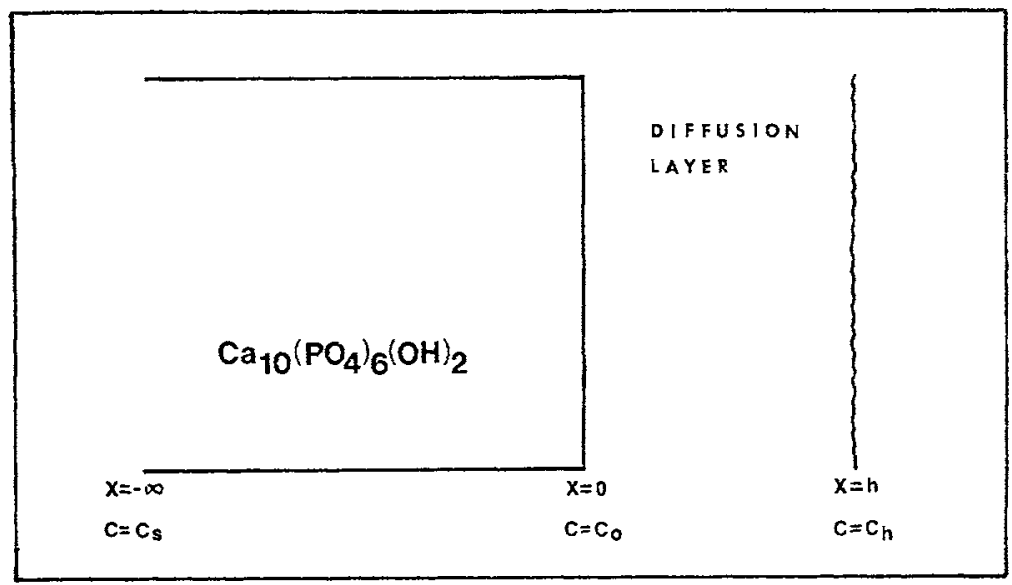

FIG 1.-Schematic representation of model.

are two regions of the system that should be considered in developing the appropriate equations for describing the rate of dissolution.

First, the dissolution behavior within the pellet should be examined. For the instance of one-component solute dissolution obeying first-order surface reaction kinetics, we may write

$$
\frac{\partial c}{\partial t}=D^{\prime} \frac{\partial^{2} C}{\partial x^{2}}+k\left(C_{s}-C\right),
$$

where $C_{s}$ is the "solubility" of the solute; $k$, the apparent first-order surface reaction rate constant; and $D^{\prime}$, the effective diffusivity in the pellet. $C$ is the solution concentration in the pores of the pellet at time $t$ and position $x$. For the steady state, which is generally attained in relatively short periods of time, equation $I$ becomes

$$
D^{\prime} \frac{\mathrm{d}^{2} C}{\mathrm{~d} x^{2}}+k\left(C_{s}-C\right)=0 .
$$

The other region of concern is the diffusion layer $(0 \leqslant x \leqslant h)$ (see Fig 1). The flux of solute in this region may be expressed by the Noyes-Nernst equation 8

$$
J=\frac{D A}{h}\left(C_{o}-C_{h}\right)
$$

where $A$ is the area of pellet surface; $h$, the diffusion layer thickness; $C_{o}$ and $C_{h}$, the concentrations at the pellet-solution interface $(x=0)$ and in the bulk $(x \geqslant h)$, respectively; and $D$, the solute diffusivity in water.

Using appropriate boundary conditions and recalling that in the steady state at $x=0$ the flux out of the pellet may be equated to the flux in the pellet at $x=0$,

$$
\begin{aligned}
J= & \frac{d Q}{d t}=-A D^{\prime}\left(\frac{d C}{d x}\right)_{\alpha=0} \\
= & \frac{D A}{h}\left(C_{o}-C_{h}\right) .
\end{aligned}
$$

The analytical solution for equations 2 and 3 can then be obtained as

$$
\begin{gathered}
\frac{J}{A}=\frac{C_{s}-C_{h}}{\frac{h}{D}+k^{\prime}} \\
C=C_{s}-\frac{D}{h} \frac{C_{s}-C_{h}}{\frac{1}{k^{\prime}}+\frac{D}{h}} \times \\
\exp \left(\left(k / D^{\prime}\right)^{1 / 2} \cdot x\right) \text { for } x \leqslant 0,
\end{gathered}
$$

where $k^{\prime}=\left(k \cdot D^{\prime}\right)^{-1 / 2}$.

If a $D^{\prime}$ value of $1 \times 10^{-6} \mathrm{~cm}^{2} / \mathrm{sec}$ is assumed, one finds that the relevant reaction zone would have a depth of about 5 micrometers $(\mu \mathrm{m})$. Figure 2 shows the nature of the reaction zone and the concentration profile in the aqueous pores of a hydroxyapatite pellet according to equation 6 .

Frank-Kamenetskii ${ }^{9}$ derived an equation similar in form to equation 6 for the overall rate in a reaction involving porous materials. However, his situation differs physically from this work in that he considered only the reactant diffusion-controlled case and consequently ignored the driving factor, $C_{8}$.

It has been shown in this study and in 


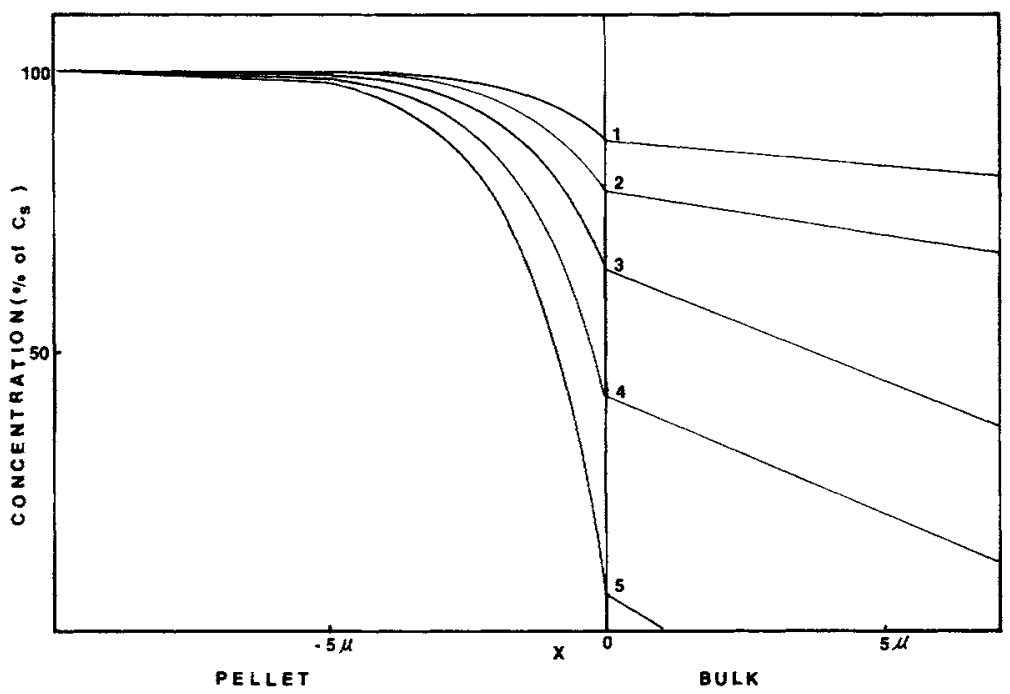

Fic 2.-Concentration profiles for hydroxyapatite dissolution under sink conditions and different hydrodynamic conditions. Key: (1) difussion layer thickness, $h=100 \mu \mathrm{m}$; (2) $\mathrm{h}=50 \mu \mathrm{m}$; (3) $h=25 \mu \mathrm{m}$; (4) $\mathrm{h}=10 \mu \mathrm{m}$; (5) $\mathrm{h}=\mathbf{l} \mu \mathrm{m}$.

others $^{3}$ that hydroxyapatite dissolution in acetate buffers is a congruent reaction. Thus we may write

$$
\begin{gathered}
\mathrm{Ca}_{10}\left(\mathrm{PO}_{4}\right)_{8}(\mathrm{OH})_{2}+8 \mathrm{H}^{+} \stackrel{k}{\longrightarrow} \\
10 \mathrm{Ca}^{2+}+6 \mathrm{HPO}_{4}^{2-}+2 \mathrm{H}_{2} \mathrm{O} .
\end{gathered}
$$

Equation 7 does not necessarily give the mechanism but merely expresses the net reaction. Now, by applying equation 4 to all species and assuming that the apparent diffusivities for all the species are equal, the following equations for the dissolution rate may be obtained

$$
\begin{aligned}
\frac{J_{T \mathrm{P}}}{A} & =\frac{[T \mathrm{P}]_{8}-[T \mathrm{P}]_{h}}{k^{\prime}+h / D}, \\
\frac{J_{T \mathrm{Ca}}}{A} & =\frac{[T \mathrm{Ca}]_{8}-[T \mathrm{Ca}]_{h}}{k^{\prime}+h / D},
\end{aligned}
$$

and

where

$$
J_{\mathrm{TCa}}=1.67 J_{T \mathrm{P}}
$$

$$
\begin{aligned}
& {[\mathrm{TP}]=\left[\mathrm{H}_{3} \mathrm{PO}_{4}\right]+\left[\mathrm{H}_{2} \mathrm{PO}_{4}^{-}\right]+\left[\mathrm{HPO}_{4}{ }^{2-}\right]} \\
& +\left[\mathrm{PO}_{4}{ }^{3-}\right]+\left[\mathrm{CaHPO}_{4}\right]+\left[\mathrm{CaH}_{2} \mathrm{PO}_{4}{ }^{+}\right]
\end{aligned}
$$
and

$$
\begin{aligned}
{[\mathrm{TCa}]=} & {\left[\mathrm{Ca}^{2+}\right]+\left[\mathrm{CaHPO}_{4}\right]+} \\
& {\left[\mathrm{CaH}_{2} \mathrm{PO}_{4}^{+}\right]+[\mathrm{CaB}] . }
\end{aligned}
$$

Here the bracketed terms are the concentra- tions and $B$ represents the buffer anion that is the acetate ion in the present study.

The use of a single $k$ for the surface reaction rate constant is equivalent to assigning the same interfacial transfer coefficient to all the species. Whether or not this is a reasonable assumption may be judged by how well the experimental data fit the model. This important issue and its implications will be discussed later.

In addition to the rate equations, the following equilibriums must be considered at various places in the entire system.

$$
\begin{aligned}
\mathrm{H}_{3} \mathrm{PO}_{4} & \rightleftarrows \mathrm{H}_{2} \mathrm{PO}_{4}^{-}+\mathrm{H}^{+}, \\
\mathrm{H}_{2} \mathrm{PO}_{4}^{-} & \rightleftarrows \mathrm{HPO}_{4}^{2-}+\mathrm{H}^{+}, \\
\mathrm{HPO}_{4}^{2-} & \rightleftarrows \mathrm{PO}_{4}^{3-}+\mathrm{H}^{+}, \\
\mathrm{H} B & \rightleftarrows \mathrm{H}^{+}+B^{-}, \\
\mathrm{CaHPO}_{4} & \rightleftarrows \mathrm{Ca}^{2+}+\mathrm{HPO}_{4}^{2-}, \\
\mathrm{CaH}_{2} \mathrm{PO}_{4}^{+} & \rightleftarrows \mathrm{Ca}^{2+}+\mathrm{H}_{2} \mathrm{PO}_{4}^{-}, \\
\mathrm{Ca} B^{+} & \rightleftarrows \mathrm{Ca}^{2+}+\mathrm{B}^{-},
\end{aligned}
$$

and

$$
\mathrm{H}_{2} \mathrm{O} \rightleftarrows \mathrm{H}^{+}+\mathrm{OH}^{-} \text {. }
$$

The ionic activity product of hydroxyapatite in solution at the crystal surface may be defined as follows: 


$$
\begin{aligned}
K_{H A P}= & a_{\mathrm{Ca}^{2+}}{ }^{10} a \mathrm{PO}_{4}^{3-6} a^{10} \mathrm{Ca}^{2+} a^{6} \mathrm{PO}_{4}^{3-} a_{\mathrm{OH}-} \\
& =\left[\mathrm{Ca}^{2+}\right]_{8}^{10}\left[\mathrm{PO}_{4}^{3-}\right]_{8}^{6}\left[\mathrm{OH}^{-}\right]^{2} \\
& \left(\gamma_{\mathrm{Ca}^{2+}}\right)^{10}{ }_{8}^{10}\left(\mathrm{PO}_{4}{ }^{3-}\right)_{8}^{6}\left(\gamma_{\mathrm{OH}}-\right)_{8}^{2,}
\end{aligned}
$$

where $a_{\mathrm{Ca} 2+}$ and so on are ionic activities and $\gamma_{\mathrm{Ca}^{2+}}$, and so on are the ionic activity coeffcients of individual species.

Now $h, A$, and $D$, the concentrations of species in the bulk and all the equilibrium constants, are either known of or may be estimated. $J_{T P}$ and $J_{T \mathrm{Ca}}$ can be determined by experiments. Thus $\left[\mathrm{Ca}^{2+}\right]_{s},\left[\mathrm{PO}_{4}{ }^{3-}\right]_{s}$ and $\left[\mathrm{OH}^{-}\right]_{s}$ and $k^{\prime}$ can be calculated from equations 8 to 21 by digital computation. Also, $\gamma_{\mathrm{Ca}^{2+}}, \gamma_{\mathrm{PO}_{4} 3^{-}}$and $\gamma_{\mathrm{OH}_{-}}$may be estimated from the literature (see Appendix). Therefore, $K_{H A P}$ and the apparent dissolution rate constant, $k^{\prime}$, may be obtained from the experimental dissolution rates and the equations. It is important to recognize that the $K_{H A P}$ given by equation 21 is not necessarily the solubility product for hydroxyapatite. It is defined here as the ionic activity product for hydroxyapatite prevailing at the crystal-solution interface and determining the dynamic conditions for steady state dissolution.

The rotating disk mathematics.-The equation that describes the mass transport from a rotating disk under constant angular velocity was given by Levich ${ }^{10}$ as

$$
J / A=0.62 D^{2 / 3} v^{-1 / \omega_{\omega}}{ }^{1 / 2}\left(C_{o}-C_{h}\right),
$$

where $v$ is the kinematic viscosity of the medium and $\omega$ is the angular velocity. The other constants have been defined already. By comparing equation 22 with the NoyesNernst mass transport equation (see equation 3), the diffusion layer thickness, $h$, for the rotating disk may be expressed as

$$
h=1.612 D^{1 / 3} v^{1 / 6} \omega^{-1 / 2} \text {. }
$$

EXPERIMENTS.-Preparation of hydroxyapatite.-Hydroxyapatite was prepared by a precipitation method. 5 The product was checked by infrared, X-ray diffraction and elemental analysis. The dissolution rate behavior of this sample has been compared to a sample provided by Dr. P. R. Patel of the National Bureau of Standards and the results were found to be identical under several test conditions.

HYDRoXYAPATITE PELLET.-The hydroxyapatite sample was equilibrated overnight in a humidity chamber that contained saturated potassium nitrate aqueous solution. About
$30 \mathrm{mg}$ of this humidified sample was compressed in a 0.25 -inch diameter die with a force of $10,000 \mathrm{lb}$. The resulting pellet was fixed in the disk as shown in Figure 2, with beeswax.

Solutions.-All the solutions were prepared by dissolving analytical grade chemicals in double-distilled water. Sodium chloride was added to maintain the ionic strength at 0.5 for all the solutions.

Dissolution study.-Figure 3 shows a schematic representation of the experimental rotating disk dissolution apparatus. The disk assembly was connected to a constant speed rotating mechanism. ${ }^{\mathrm{a}} \mathrm{A}$ buffer solution of $50 \mathrm{ml}$ was accurately pipetted into a jacketed 250-ml beaker and allowed to reach thermal equilibrium at $30 \mathrm{C}$. The disk containing the pellet was immersed into the solution and the motor and timer were simultaneously started. Five-milliliter samples were withdrawn by pipet at suitable intervals. The samples were diluted and analyzed as will be described.

Nearly perfect sink conditions were mainIIl.

"Servodyne, Cole Parmer Instrument Co., Chicago,

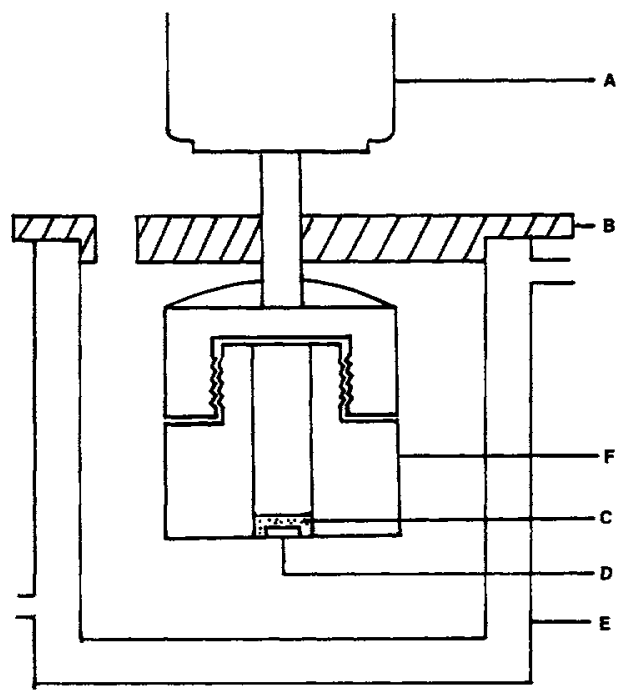

Fic 3.-Rotating disk experimental setup. Key: $A$, constant speed motor; $B$, cover; $C$, beeswax; $D$, hydroxyapatite pellet; $E$, jacketed beaker $(250$ $\mathrm{ml}$ ) ; $F$, rotating disk (height, 1.7 inches; diameter, 1.1 inches). 
tained at all times during the dissolution experiments. The amount dissolved never exceeded $1 \%$ of saturation which corresponds to an activity product of $1 \times 10^{-124}$ for the effective hydroxyapatite solubility in the medium. Also, the experimental results were identical whether or not the withdrawn solutions were replaced by fresh buffer solutions.

Calcium concentrations were measured by atomic absorption. ${ }^{\mathrm{h}}$ Because of possible phosphate interference, strontium chloride was added to each sample. Phosphate concentrations were determined by the method of Gee, Domingues, and Deitz ${ }^{11}$ in which the phospho-ammonium-molybdate complex formed was reduced by stannous chloride. The absorbance of the resulting color was determined at the end of 15 minutes at $\lambda=$ $720 \mathrm{~m} \mu c^{c}$

\section{Results}

EXPERIMENTAL RESULTS.-Figure 4 shows some typical experimental results in which the amounts of hydroxyapatite dissolved were calculated on the basis of the phosphate or

b Perkin Elmer Atomic Absorption Model 330, Perkin-Elmer Corp., Norwalk, Conn.

c Hitachi 690 Spectrophotometer, E. H. Sargent \& Co., Detroit, Mich. calcium data or both. In every case, when both analyses were done, the dissolution was found to be congruent. Also, in every case, the data showed excellent linearity with time. In Figures 5, 6, and 7, the dissolution rates are plotted against the square root of the rotation speed.

In most cases, the reproducibility of the experimental results was very good. Typically, the dissolution rates calculated from the experimental data were repeatable to about $4 \%$. These data show the influence of rotation speed on the hydroxyapatite dissolution rate in the presence and absence of the common ions, phosphate and calcium. It can be seen for all sets of data given here (Figs 5, 6, 7) that at low agitation speeds the rates become almost linear with $\omega^{1 / 2}$ and are therefore mostly diffusion controlled. At the higher speeds, the rates significantly deviate from linearity, indicating a substantial contribution of surface resistance to the dissolution reaction rate.

Theoretical Galculations AND THE DETERMINATION OF $K_{\text {HAP }}$ AND $k^{\prime}$.-The experimental data shown in Figures 5, 6, and 7 were treated using the procedure obtained in the theoretical section. Using equations 8

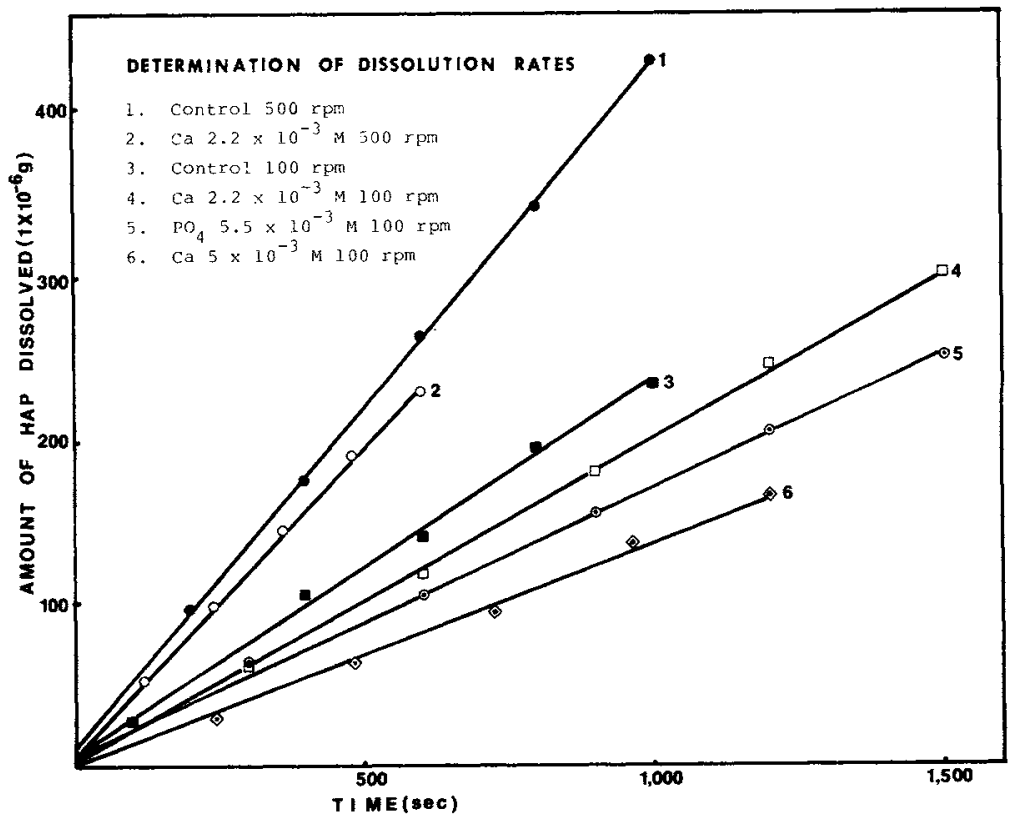

Frg 4.-Amount of hydroxyapatite dissolved in $\mathrm{pH}$ of $4.5,0.1 M$ acetate buffer solutions as function of time. Key: solid circle, $500 \mathrm{rpm}-$ control; open circle, $2.2 \times 10^{-3} \mathrm{M}$ calcium; solid square, $100 \mathrm{rpm}-\mathrm{control;}$ open square, 2.2 $\times 10^{-3} M$ calcium; dotted open circle, $5.5 \times 10^{-3} M$ phosphate; dotted open diamond, $5 \times 10^{-3} M$ calcium. 


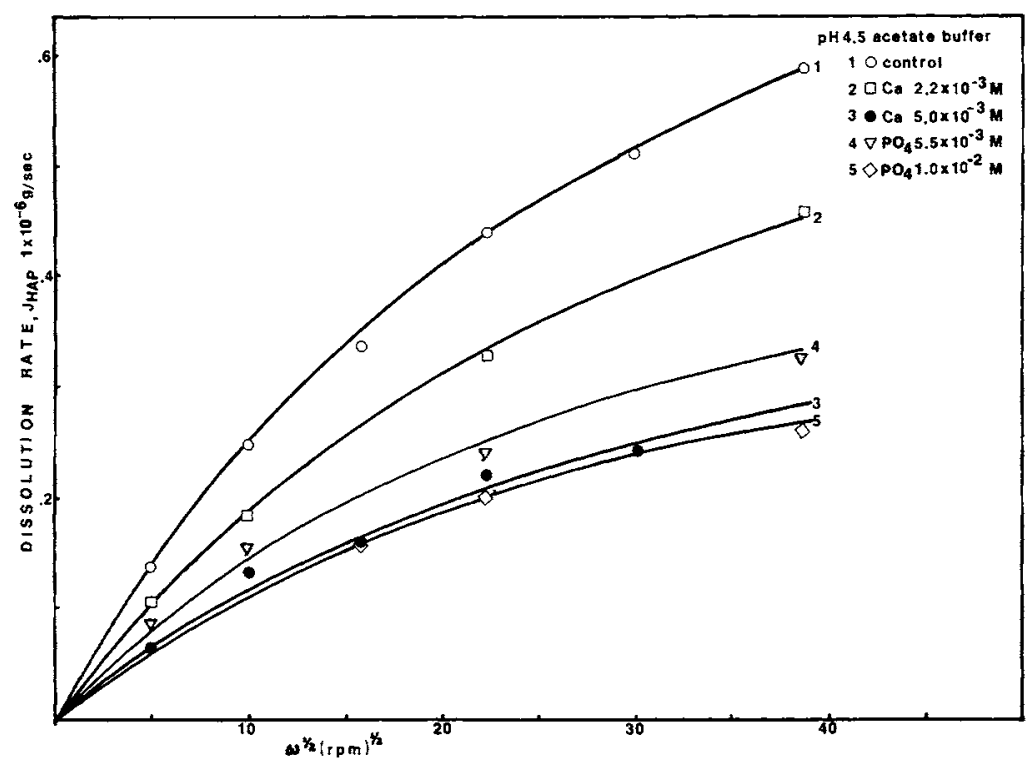

FIG 5.-Comparison of experimental results and model calculations with $K=10^{-124.5}$ and $k^{\prime}=1.74 \times 10^{2} \mathrm{sec} / \mathrm{cm}$ in $\mathrm{pH}$ of $4.5,0.1 \mathrm{M}$ acetate buffers under various rotating speeds and different common ion concentrations. Key: open circle, control; open square, $2.2 \times 10^{-3} \mathrm{M}$ calcium; open triangle, $5.5 \times$ $10^{-3} M$ phosphate; solid circle, $5.0 \times 10^{-3} M$ calcium; open diamond, $1 \times 10^{-2}$ $M$ phosphate.

\section{TABLE}

Selected Parameter Values Used in the Calculations (Ionic Strength Adjusted to 0.5 WITH NACL)

\begin{tabular}{lllc}
\hline Species & $\begin{array}{c}\text { Ionic Activity } \\
\text { Coefficient }(\gamma)\end{array}$ & Species & $\begin{array}{c}\text { Ionic Activity } \\
\text { Coefficient }(\gamma)\end{array}$ \\
\hline $\mathrm{H}_{3} \mathrm{PO}_{4}$ & 1.0 & $\mathrm{Ca}^{2+}$ & 0.33 \\
$\mathrm{H}_{2} \mathrm{PO}_{4}^{-}$ & 0.44 & $\mathrm{CaAc}^{+}$ & 0.80 \\
$\mathrm{HPO}_{4}^{2-}$ & 0.15 & $\mathrm{CaHPO}_{4}$ & 1.0 \\
$\mathrm{PO}_{4}^{2-}$ & 0.029 & $\mathrm{CaH}_{2} \mathrm{PO}_{4}^{+}$ & 0.44 \\
$\mathrm{HAc}_{\mathrm{Ac}}$ & 1.0 & $\mathrm{H}^{+}$ & 0.80 \\
& 0.80 & $\mathrm{OH}^{-}$ & 0.69 \\
\hline
\end{tabular}

\begin{tabular}{|c|c|c|}
\hline \multirow[b]{2}{*}{ Reaction } & \multicolumn{2}{|c|}{ Equilibrium Constant } \\
\hline & $\frac{\mathrm{pk}_{\mathbf{2}}}{\text { (thermodynamic) }}$ & $\underset{\text { (corrected for } \gamma)}{\mathrm{pK}_{\mathrm{k}}}$ \\
\hline $\mathrm{H}_{3} \mathrm{PO}_{4} \rightleftarrows \mathrm{H}_{2} \mathrm{PO}_{4}^{-}+\mathrm{H}^{+}$ & 2.16 & 1.70 \\
\hline $\mathrm{H}_{2} \mathrm{PO}_{4}^{-} \rightleftarrows \mathrm{HPO}_{4}^{2-}+\mathrm{H}^{+}$ & 7.19 & 6.63 \\
\hline $\mathrm{HPO}_{4}^{2-} \rightleftarrows \mathrm{PO}_{4}^{3-}+\mathrm{H}^{+}$ & 12.33 & 11.51 \\
\hline $\mathrm{HAc} \rightleftarrows \mathrm{Ac}^{-}+\mathrm{H}^{+}$ & 4.76 & 4.56 \\
\hline $\mathrm{CaAc} \mathrm{Ac}^{+} \rightleftharpoons \mathrm{Ca}^{2+}+\mathrm{Ac}^{-}$ & 1.26 & 0.773 \\
\hline $\mathrm{CaHPO}_{4} \rightleftharpoons \mathrm{Ca}^{2+}+\mathrm{HPO}_{4}^{2-}$ & 2.58 & 1.27 \\
\hline $\mathrm{CaH}_{2} \mathrm{PO}_{4}^{+} \rightleftarrows \mathrm{Ca}^{2+}+\mathrm{H}_{2} \mathrm{PO}_{4}^{-}$ & 1.00 & 0.519 \\
\hline $\mathrm{HOH} \rightleftarrows \mathrm{H}^{+}+\mathrm{OH}^{-}$ & 15.74 & 15.49 \\
\hline
\end{tabular}




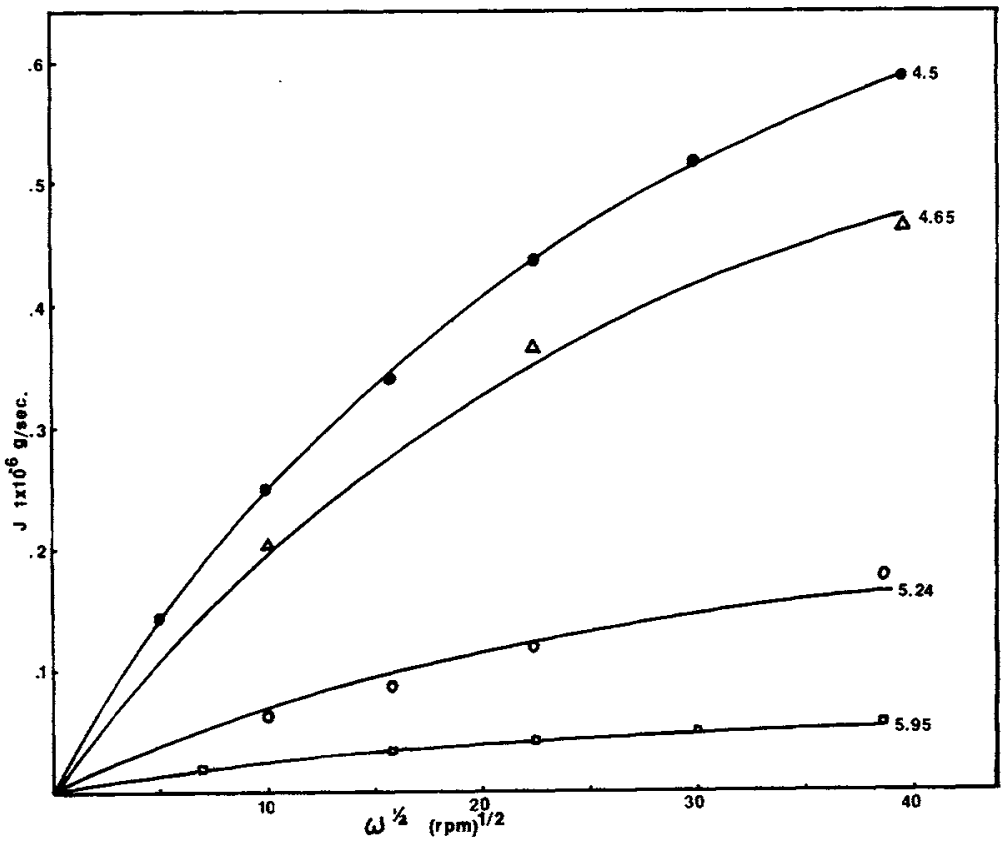

Fic 6.-Effect of $\mathrm{pH}$ on hydroxyapatite dissolution rates in $0.1 M$ acetate buffers. Symbols represent experimental results and smooth curves are model calculations with $K=10^{-124.5}$ and $k^{\prime}=1.74 \times 10^{2} \mathrm{sec} / \mathrm{cm}$. Key: solid circle, $\mathrm{pH}$ of 4.5 ; open triangle, $\mathrm{pH}$ of 4.65 ; open circle, $\mathrm{pH}$ of 5.24 ; open square, $\mathrm{pH}$ of 5.95 .

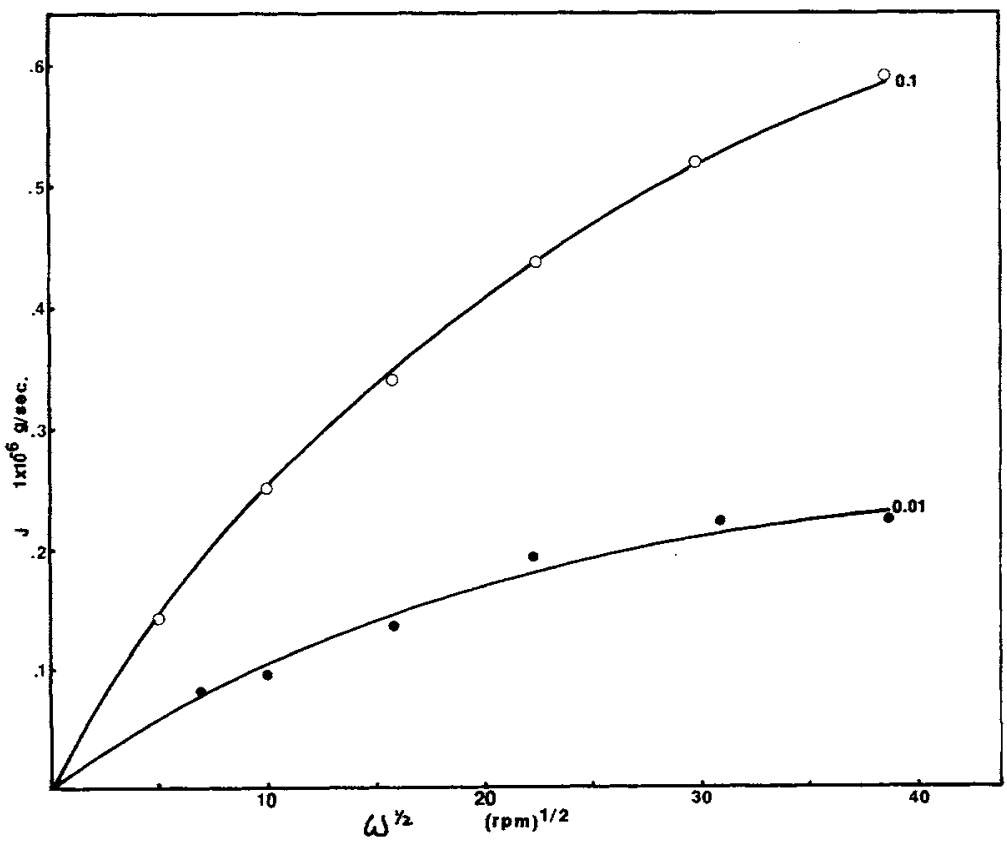

Fig 7.-Buffer capacity effect on hydroxyapatite dissolution rates. Symbols represent experimental resuits and smooth curves are model calculations with $K=10^{-124.5}$ and $k^{\prime}=1.74 \times 10^{2} \mathrm{sec} / \mathrm{cm}$. Key: open circle, $\mathrm{pH}$ of $4.5,0.1 M_{;}$ closed circle, $\mathrm{pH}$ of 4.46, $0.01 M$. 
to 21 and the equilibrium constants and ionic activity coefficients given in the table, the best pair of the $K_{H_{A} P}$ and $k^{\prime}$ were found that were consistent with all the experiments.

In these calculations, a diffusion coefficient of $1 \times 10^{-5} \mathrm{~cm}^{2} / \mathrm{sec}$ was assumed for the diffusivities of all the species. This treatment of data with the theory yielded a $K_{H A P}$ value of $1 \times 10^{-125} \pm 0.5$ and a $k^{\prime}$ value of $145 \pm 5$ $\mathrm{sec} / \mathrm{cm}$. The theoretical hydroxyapatite dissolution rates corresponding to $K_{H A P}=1 \times$ $10^{-125}$ and $k^{\prime}=145$ are shown in Figures 5, 6 , and 7 as smooth curves. As can be seen, the agreement of experimental results with theory is very good.

\section{Discussion}

POSSIBLE ERRORS IN THE ANALYSIS.-There are several contributions to the uncertainty in the analysis. First, there are some uncertainties in the use of the Levich equation (equation 22) for the present experimental arrangement. Baseline studies with benzoic acid pellets ${ }^{12}$ with the present assembly (Fig 2) have consistently yielded rates that are about 15 to $20 \%$ less than those predicted by equation 22. If a correction is made for this discrepancy, the deduced $K_{H A P}$ value would be about $I \times 10^{-124.5}$ and that for $k^{\prime}$ would be $174 \mathrm{sec} / \mathrm{cm}$.

Uncertainties may also arise because of uncertainties in the choice of the activity coeffcients and in the assignment of $1 \times 10^{-5}$ $\mathrm{cm}^{2} / \mathrm{sec}$ for all the diffusivities $(D)$. Both the value for $D$ and values for the activity coefficients (Table) are believed to be reasonably good choices and they have been supported by independent studies (see Appendix).

It is suggested, therefore, that $K_{H A P}=$ $10^{-124.5}$ and $k^{\prime}=174 \mathrm{sec} / \mathrm{cm}$ should be the best pair representative of the data with a probable uncertainty in the exponent for $K_{I I A P}$ of about 1.0 .

The PHysigal MEANing of $K_{\text {Hap }}$-Under sink conditions, hydroxyapatite may dissolve rapidly with a crystal surface ionic activity product of $K_{I I A P}=1 \times 10^{-124.5}$ governing the dissolution reaction. This activity product would correspond to a molar solubility that is only about one fifth of the thermodynamic solubility $\left(K_{s p}-10^{-116}\right) .5,6$

Therefore, these results may be explained on the basis of the predominant dissolving site under sink conditions being the one possessing a solubility that is significantly less than the true thermodynamic value. This low solubility should actually be viewed as the necessary activity product for rapid ion disengagement from a site requiring a substantial undersaturation for rapid dissolution.

It is noteworthy that similar results with human dental enamel blocks were obtained previously ${ }^{1-3}$ and verified more recently. The corresponding $K_{H A P}$ for block enamel dissolution was found to be about $10^{-125}$ in good agreement with the present data for hydroxyapatite crystals.

Weak acid etch of enamel13,14 has shown that preferential dissolution occurs at the prism centers where the crystals are predom. inantly oriented with the c-axis perpendicular to the surface. Also, weak acid attack of enamel crystallites ${ }^{15}$ has shown a shorten. ing of the c-axis. Therefore, together, the kinetic data and the morphological observations suggest that the general location of the $10^{-124.5}$ site might be the c-plane of the hydroxyapatite crystal. Direct correlative studies are essential, however, before this may be considered a fact.

The MeAning of $k^{\prime}$.-The present analysis has shown that the surface reaction resistance contributes significantly at the higher agitation conditions. The generally good fit of the experimental data to the model, especially at the large rotating speeds, strongly support the assumption that a single $k$ value may be used for all species. Calculations for the general case, that is, where the $k s$ are permitted to be arbitrarily different for the different species, show that the correlation between experiment and theory is poor when the $k$ for $\mathrm{Ca}$ and the $k$ for the phosphate species are assumed to be significantly different, for example, by about a factor of five.

A detailed analysis of the meaning of $k$ is presently being completed in a study where various combinations of $k$ s for each species are used in the theoretical calculations. It appears, for example, that the good fit of the theory with a single $k$ value may be essentially equivalent to the case in which $k_{B}=$ $k_{H}=0$ and $k_{H}>>k_{\text {other species. }}$

\section{Conclusions}

The model given in this report and the rotating disk method provide a useful combination in the study of dental enamel and hydroxyapatite dissolution kinetics. The present approach is a significant improve- 
ment over earlier studies, $1-3,16$ and both the ionic activity product that governs the dissolution reaction and the apparent surface dissolution reaction rate constant may be simultaneously obtained. Thus, these investigations have established the baseline for the dissolution rate studies under sink conditions.

Concurrent studies 17,18 under conditions where the acidic buffer mediums are partially saturated with respect to hydroxyapatite have shown another dissolution site for hydroxyapatite that operates at a higher ionic activity product but has a much smaller apparent surface reaction rate constant. This has raised the question of whether the presence of this second site may interfere with the proper theoretical analysis of the experimental results obtained under sink conditions. A preliminary analysis of the two-site model has shown that the dissolution kinetics of hydroxyapatite under sink conditions is almost completely governed by the sink condition site $\left(K_{H A}=10^{-124.5}, k^{\prime}=174\right)$ established in this report. The difference between the predicted dissolution rate for the one-site model and the two-site model are generally of the order of 4 to $5 \%$ where the experiments are conducted under sink conditions and over the range of variables covered in the present study.

\section{Appendix}

ACTIVITY COEFFICIENTS. - The ionic activity coefficients listed in the table were estimated from various experimental mean activity coefficients of corresponding salts at ionic strength, $\mu$ equal to $0.5 .{ }^{19,20}$ A detailed procedure of how this was done is presented in Wu's PhD thesis. 21 The suitability or "goodness" of this set has been independently supported by solubility experiments with dicalcium phosphate dihydrate in a $\mathrm{pH}$ of $4.5,0.1$ $M$ acetate buffer at ionic strength $\mu=0.5$ $(\mathrm{NaCl})$. The $K_{s p}$ calculated from these results and the activity coefficients listed in the table were found to be in good agreement with that determined by Gregory, Moreno, and Brown, 21 that is, $2.06 \times 10^{-7}$ vs $2.51 \times$ $10^{-7}$ for the $K_{s p}$ interpolated at $30 \mathrm{C}$. Another independent check on the method used to estimate the activity coefficients given in the table was made by analyzing the solubility data ${ }^{22}$ of thallous chloride. ${ }^{21}$ A fairly constant $K_{s p}$ for thallous chloride was found with the ionic strength up to about $\mu=0.5$ using the present method for estimating the activity coefficients.

It is important to point out here that this new set of activity coefficients (Table) compares favorably with the older set used in our previous publications.24-26 For example, the set of activity coefficients recently used by Dedhiya, Young, and Higuchi ${ }^{24}$ in their studies on the influences of strontium on TVA hydroxyapatite dissolution would yield a $K_{H A P}$ of $1 \times 10^{-125}$ instead of $1 \times$ 10-124.5.

Diffusivity, $D=1 \times 10^{-5}$.-This value for $D$ has been used in all of our past studies. Its choice was first based on theoretical and empirical considerations. ${ }^{1}$ Later, experimental estimates were made 26.27 for the effective or apparent $D$ for the "system."

Most recently, ${ }^{21}$ the $D$ value was independently estimated by doing dissolution rate experiments with dicalcium phosphate dihydrate pellets under the same conditions (pH, 4.5; $0.1 M$ acetate buffer, $\mu=0.5$ ) used in this report. These data together with the experimental solubility, $C_{s}$, used with the Levich equation (equation 22) and a best $D$ value of $(0.97 \pm 0.10) \times 10^{-5} \mathrm{~cm}^{2} /$ sec were obtained.

I TVA hydroxyapatite is a sample prepared by a high temperature $(\sim 1,200 \mathrm{C})$ reaction. ${ }^{24}$

\section{References}

1. Higughi, W.I.; Gray, J.A.; HeFFERren, J.J.; and PATEL, P.R.: Mechanism of Enamel Dissolution in Acid Buffers, $J$ Dent Res 44: 330 $341,1965$.

2. Higuchi, W.I.; Patel, P.R.; and HefFerRen, J.J.: Quantitation of Enamel Demineralization Mechanisms: II, I Pharm Sci 54:587$590,1965$.

3. Higuchi, W.I.; MIR, N.A.; PATel, P.R.; BeCKer, J.W.; and HeFFrerReN, J.J.: Quantitation of Enamel Demineralization Mechanisms: III. A Critical Examination of the Hydroxyapatite Model, J Dent Res 48: 396$409,1969$.

4. MIR, N.A., and HiguchI, W.I.: The Mechanism Of Action of Solution Fluoride upon the Demineralization Rate of Human Enamel, Arch Oral Biol 14: 901-920, 1969.

5. Avnimelich, Y.; Moreno, E.C.; and Brown, W.E.: Solubility and Surface Properties of Finely Divided Hydroxyapatite, $J$ Res Nat Bureau Standards 77A (suppl) : 149-155, 1972.

6. Moreno, E.C.; Gregory, T.M.; and Brown, W.E.: Preparation and Solubility of $\mathrm{Hy}$ droxyapatite, $J$ Res Nat Bureau Standards 72A (suppl) : 773-782, 1968. 
7. NANCOLLAS, G.H.: Physicochemistry of Enamel Demineralization and Remineralization, J Dent Res 53: 297-302, 1974.

8. Higuchi, W.I.: Diffusion Model Useful in Biopharmaceutics, J Pharm Sci 56: 315-324, 1967.

9. Frank-Kamenetskir, D.A.: Diffusion and Heat Transfer in Chemical Kinetics, New York: Plenum Press, 1969, p 103.

10. Levich, V.G.: Physicochemical Hydrodynamics, New York: Prentice-Hall, Inc., 1962.

II. GeE, A.; Domingues, L.P.; and DeITz, V.R.: Determination of Inorganic Constituents in Sugar, Anal Chem 26: 1487-1492, 1954.

12. Wu, M.S., and Prakongpai, S.: Unpublished data, 1975.

13. JoHnson, N.W.; POOLE, D.F.G.; and TYLer, J.Z.: Factors Affecting the Differential Dissolution of Human Enamel in Acid and EDTA: A Scanning Electron Microscope Study, Arch Oral Biol 16: 384-392, 1971.

14. Nichol, T.; JudD, G.; and ANseld, G.S.: A Two-Stage Model for Human Enamel Demineralization as Determined by Scanning Electron Microscope Analysis, J Dent Res 52: 487-493, 1973.

15. JoHnson, N.W.: Differences in the Shape of Human Enamel Crystallites after Partial Destruction by Caries, EDTA and Various Acids, Arch Oral Biol 11: 1421-1423, 1966.

16. Gray, J.A.: Kinetics of the Dissolution of Human Dental Enamel in Acid, $J$ Dent Res 41: 633-645, 1962.

17. DedhiYa, M.G.; Young, F.; Heffreren, J.J.; and Higuchl, W.I.: The Inhibition of Hydroxyapatite Dissolution by $\mathrm{Sr}^{2+}$ and $\mathrm{Mg}^{2+}$ under Partial Saturated Conditions in Solutions Containing $\mathrm{F}^{-}, J$ Dent Res (Special Issue): Abstract No. 204, 1974.

18. Young, F.; FAWZI, M.; DedhiYa, M.G.; WU, MS; and Higuchi, W.I.: Dual Mechanisms for Dental Enamel Dissolution in Acid Buf- fers, $J$ Dent Res (Special Issue): Abstract No. $576,1974$.

19. Robinson, R.A., and STOKEs, R.H.: Electrolyte Solutions, London: Butterworth, 1959.

20. Gregory, T.M.; Moreno, E.C.; and Brown, W.E.: Solubility of $\mathrm{CaHPO}_{4} 2 \mathrm{H}_{2} \mathrm{O}$ in the System $\mathrm{Ca}(\mathrm{OH})_{2}-\mathrm{H}_{3} \mathrm{PO}_{4}-\mathrm{H}_{2} \mathrm{O}$ at $5,15,25$ and $37.5^{\circ} \mathrm{C}, J$ Res Nat Bureau Standards 74A: $461-475,1970$.

21. Wu, M.S.: Kinetics of Hydroxyapatite Dissolution and Influence of Foreign Ions Under Sink Conditions, PhD thesis, Ann Arbor, Michigan: University of Michigan, 1975.

22. Bray, W.C., and Winninghoff, W.J.: The Effect of Salts on the Solubility of Other Salt: III. Solubility of Thallous Chloride in Solution of Potassium Nitrate, Potassium Sulfate and Thallous Sulfate at $25^{\circ} \mathrm{C}, J \mathrm{Am}$ Chem Soc 33: 1663-1672, 1911.

23. Dedhiya, M.G.; Youne, F.; and Higuchi, W.I.: Mechanism for the Retardation of the Acid Dissolution Rate of Hydroxyapatite by Strontium, J Dent Res 52: 1097-1109, 1973.

24. DedhiYA, M.G.; Young, F.; and Higuchi, W.I.: Mechanism of Hydroxyapatite Dissolution: The Synergistic Effects of Solution Fluoride, $J$ Phys Chem 78: 1273-1279, 1974.

25. LiANG, Z.S., and Higuchi, W.I.: Kinetics and Mechanism of the Reaction Between Hydroxyapatite and Fluoride in Aqueous Acid Media, $J$ Phys Chem 77: 1704-1710, 1973.

26. Hodfs, B.: Dissolution Rate Studies of Some Calcium Phosphates Using the Rotating Disk Method, PhD thesis, Ann Arbor, Michigan: University of Michigan, 1971.

27. Hwu, R.C.: Kinetics and Mechanism of Dicalcium Phosphate Dihydrate to Fluoroapatite Conversion in Fluoride Solutions, $\mathrm{PhD}$ thesis, Ann Arbor, Michigan: University of Michigan, 1974. 